\title{
0 Apocalipse de João e a interpretação cosmológica do mundo Romano
}

\author{
The Apocalypse of John and the cosmological \\ interpretation of the Roman world
}

\section{Kenner Terra*}

Faculdade Unida de Vitória, Vitória, ES, Brasil

\section{Resumo}

O Apocalipse de João é uma obra instigante. Sua linguagem cheia de violência, com monstros aterrorizantes, pessoas clamando por justiça, anúncios de mortes e desespero, em um quadro de espetáculos celestes, fascina os que gostam de ficção e alimenta a esperança dos que esperam um dia entrar na Nova Jerusalém, onde não haverá mar nem morte, quando as lágrimas serão enxugadas. Contudo, o livro do Apocalipse será lido como uma narração da realidade. Nesse sentido, o texto não é visto como reflexo de qualquer opressão, mas construção discursiva a respeito do sistema que, para o visionário, é a negação da ordem. Assim sendo, a tese defende o terror como instrumento de persuasão, o qual serviu, na estratégia do visionário, para descrever o seu contexto como realidade caótica. Por meio de estratégias narrativas, o narrador deseja

* KT: Doutor em Ciências da Religião, e-mail: krcroger@gmail.com 
que sua visão seja levada a sério e que seus interlocutores aceitem a sua interpretação da realidade, deixando a associação com a vida e sistema romanos, pois se assim procederem serão comparados aos selados e receberão as mesmas recompensas. Dessa maneira, sua descrição com linguagem escatológica joga com o futuro e com o presente; prevê o caos, mas o vive em nível narrativo. Por isso o livro do Apocalipse, com um dualismo extremamente radical, não dá espaços para dúvidas.

Palavras-chave: Cosmos. Narrativa. Caos. Apocalipse de João. Roma.

\section{Abstract}

The Apocalypse of John is an intriguing work. Its language filled with violence, fearsome monsters, people crying out for justice, and announcements of death and despair, in a frame of celestial spectacles, fascinates those who like fiction and nourishes hope for those who expect one day to enter the New Jerusalem, where there will be no sea or death, and when the tears will be wiped away. However, the book of Revelation will be read as a narration of reality. In this sense, the text will not be seen as a reflection of any oppression, but as a discursive construction about the system that is for the visionary the denial of order. Thus, the thesis defends terror as an instrument of persuasion that helped to describe the visionary context as a chaotic reality in his strategy. Through narrative strategies, the narrator wants to impose his vision so that his interlocutors accept his interpretation of reality and leave the association with Roman life and system, for in doing so they will be compared with the sealed and they will receive the same rewards. Hence, his description with eschatological language plays with both the future and the present; it foresees chaos, but lives it in a narrative level. Thus, the book of Revelation, with an extremely radical dualism, does not give space for doubts.

Keywords: Cosmos. Narrative. Chaos. Revelation of John. Roman.

\section{Introdução}

A literatura apocalíptica, mesmo tratando em certo ponto de especulações e presságios futuristas, deseja, como se percebe nas mais 
ressentes pesquisas (ROWLAND, 1982; ROWLAND; MORRAY-JONES, 2009), interpretar a realidade, suas funções naturais e discernir o que há de mais essencial em sua existência. Desta forma, a visão de mundo judaico-cristã desenvolvida especialmente no segundo templo é exemplo de hermenêutica dos processos históricos e naturais. É comum nos textos escritos neste locus literário a descrição de visionários que são levados para os céus, onde lhes são reveladas as funções de seres cósmicos na organização dos movimentos mais cotidianos e naturais: das chuvas ao orvalho, das práticas sociais aos conflitos entre nações, tudo funciona a partir de seres celestiais que estão sob controle divino (1 Enoque, Jubileus, Testamento de Levi, 1QM, 1QH, Gl 4, Ap 4-5, CD, 2Bar etc.).

O visionário João, o narrador interno (intradiegético) do Apocalipse, usando a linguagem comum a este gênero e vivendo na tessitura da semiosfera partilhada do primeiro século da era comum, produz um texto que representa a articulação da realidade e interpretação cosmológica do sistema romano e funcionamento da natureza que o cerca. Neste sentido, a narrativa funda mundos discursivamente, dando a ele significado e vinculações a forças não naturais. Esta se torna fonte inesgotável de sentido para realidade, o que se percebe claramente na história da recepção do Apocalipse (NOGUEIRA, 2011) ${ }^{1}$.

Neste artigo, apresentar-se-ão as possibilidades de acesso e chave de compreensão do Apocalipse. Depois de expor as hipóteses tradicionais, descrever-se-á o projeto de leitura que se preocupa com a análise narrativa e do discurso. Esta mostrará os artifícios narrativos usados pelo texto para (1) construir a imagem do sistema romano; (2) desconstruir o discurso de pax anunciado por este império e (3) criar retoricamente a sensação de caos, o que é feito através de releituras de memórias da cultura judaico-cristã.

1 Nesse artigo há uma sucinta, mas densa exposição da relação dos textos apocalípticos e seus arquétipos para a literatura mundial. Nogueira cita uma obra que merece ser visitada e analisada com calma, Los imaginários apocalípticos em la literatura hispanoamericana contemporánea, editada por Fabry Geneiéve, Ilse Logie e Pablo Decock. 


\section{Leitura do Apocalipse de João na América Latina: texto como mensagem cifrada}

Durante muito tempo o Apocalipse de João foi lido como descrição da realidade dos cristãos no Império Romano, como se o texto pudesse ser reflexo de fatos decifrados pela linguagem apocalíptica. Neste texto, depois de superar as leituras histórico-sociais feitas do livro do Apocalipse, as quais tentaram demonstrar que ele foi uma espécie de mensagem cifrada para a criação de esperança a cristãos perseguidos por Roma, será apresentada a leitura que leva em consideração as estratégias narrativas para o estabelecimento discursivo não de esperança, mas de uma leitura pessimista e de terror. Para tanto, há a relação dialógica prevista pela narrativa entre enunciador e enunciatário, os quais compartilham o conjunto de textos que transitam na semiosfera. Estes desenham o quadro de ordem a partir de uma estruturação mítica da realidade, que uma vez desfeita gera terror e desordem. Para essa instauração narrativa de terror a linguagem cheia de imagens do grotesco é preservada. Assim, o livro do Apocalipse se torna uma obra de instalação discursiva do terror, que é uma contra-argumentação à ordem prevista pelo discurso romano.

Primeiro, apresentar-se-ão as possibilidades de leitura do Apocalipse para, então, inserir este trabalho entre os que privilegiam mais a observação das estratégias narrativas do livro do que a sua adequação às realidades histórico-sociais de perseguição. Nesse sentido, o "contexto" é visto como a "memória do dizer", ou seja, a semiosfera judaico-cristã. Se o Império Romano tinha o discurso de um mundo coeso, pacífico e ordenado, no qual se integravam os âmbitos econômico, político e religioso, o discurso do Apocalipse dá indícios de desconstrução desse quadro, propondo outro olhar sobre a realidade. Este seria um contradiscurso, o qual se estrutura em diálogo com as imagens de caos comuns nas memórias da literatura enoquita ${ }^{2}$. A preocupação será, então, identificar o “contexto” criado

2 Como defende Carol Newsom, o que é característico em 1 Enoque 12-16 é a ruptura na ordem do universo. Cf. NEWSOM, 1980. 
narrativamente. Para percebermos a construção do terror e caos narratológicos, olhar-se-á a sequência narrativa temática ${ }^{3}$ das trombetas, selos e taças.

Por muito tempo, especialmente na exegese latino-americana, o livro do Apocalipse foi lido como um texto que refletia, ou nele subjazia, realidades de opressão e até mesmo martírios causados pela violência estrutural impetrada pelo Império Romano sob a coroa de Domiciano ${ }^{4}$. Nessa perspectiva, o Apocalipse foi escrito para ajudar os seguidores de Jesus a manterem a fé durante a desgraça, com a promessa de que a iminência do fim encerraria uma grande tribulação. A afirmação de Eusébio ("muitas foram as vítimas das crueldades de Domiciano" [Hist. Ecl. 3.17]) (THOMPSON, 2003, p. 30) de que esse regente romano deu muitas provas de crueldade, sendo um dos que promoveram a perseguição contra os cristãos, era uma afirmação historicamente aceita. Alguns, diferentemente, leem o texto de Irineu (Adversus Haereses 5. 30. 3) e identificam as imagens de violência e morte do Apocalipse como espelho do período do reinado de Nero (FRILINGOS, 2004, p. 2-3). Ou seja, o texto é visto como uma porta de entrada para a realidade sangrenta, marcada por perseguições. Um exemplo dessa leitura está no clássico comentário de Carlos Mesters e Francisco Orofino (MESTERS, C.; OROFINO, 2002), no qual encontramos ainda a expectativa de que o Apocalipse reflita, em algum nível, a realidade de perseguição vivida no Império Romano. Mesmo levando em consideração as dúvidas levantadas pelas pesquisas sobre a perseguição por Domiciano (8196), os autores acreditam encontrar no livro do Apocalipse a vida real do Império Romano na Ásia. Como eles mesmos dizem:

Nota-se hoje que em alguns comentários há uma tendência para diminuir o impacto da perseguição no fim do governo do Imperador Domiciano (8196) [...]. O que imporá nesta questão talvez seja definir melhor o que se entende por perseguição. De fato, é possível e provável que não tenha havido uma perseguição explícita contra os cristãos, em nível global do Império,

3 Sequência narrativa é um termo técnico da Análise Narrativa e se refere a uma unidade narrativa composta por várias micronarrativas. Ser temática diz respeito à sua estratégia na composição da narrativa, pois demonstra como determinado tema é desenvolvido e a importância de cada micro no quadro narrativo.

4 Contudo, temos trabalhos realizados no Brasil que não seguem esse caminho. Pode-se citar o ensaio de Nogueira, que afirma categoricamente: não há, de fato, muitas informações sistemáticas contra cristãos na Ásia Menor sob Domiciano. Cf. NOGUEIRA, 2003. p. 23.

Rev. Pistis Prax., Teol. Pastor., Curitiba, v. 9, n. 3, 760-784, set./dez. 2017 
decretada por Domiciano [...]. As alusões no livro do Apocalipse são demasiadas para serem negligenciadas ou desfeitas como sendo de menor importância [...]. Mesmo não havendo informação explícita extrabíblica a respeito da perseguição na época de Domiciano, estas alusões do próprio Apocalipse também são uma informação histórica dos anos 70 e 110 d.C. [...]. Como consequência desta pressão ideológica cada vez mais forte, havia também perseguição sangrenta (MESTERS, C.; OROFINO, 2002, p. 47; 51).

Nesse ponto de vista, o livro do visionário João seria uma espécie de mensagem cifrada, uma janela para o mundo do Império, onde cristãos viviam diversas crises internas e externas. Desse modo, o livro se apresenta como espelho para uma comunidade cristã que, segundo os autores, está em franca separação do judaísmo.

Outro texto latino-americano que acompanha, com algumas poucas modificações, essa perspectiva é a obra de Pablo Richard (RICHARD, 1996). Seguindo as afirmações de Paul Hanson (HANSON, 1983) de que a literatura apocalíptica surge sempre em espaços de privação, o Apocalipse é tratado por Richard como obra de setores marginalizados, pobres e humilhados, os quais produzem uma visão histórica ou teológica alternativa às dos dominantes. Assim, ele define três tipos de situações que os oprimidos podem viver e das quais podem nascer os textos apocalípticos: desintegração, perseguição e opressão. Para Richard, há uma realidade de opressão e exclusão por trás das linhas do texto que se materializava no âmbito econômico, cultural, religioso, político, cotidiano e familiar.

A realidade de exclusão é uma situação pior que a exploração e a opressão, pois o excluído fica completamente fora e não conta: sua morte não afeta o sistema [...]. O excluído não apenas vive sob violência dominante, mas, além disso, a violência entre os próprios excluídos [...]. Este é o contexto social fundamental onde nasce o Apocalipse, sem negar situações de opressão permanente e de perseguição indubitáveis, que se deram da mesma forma (RICHARD, 1996, p. 48-49).

Ainda, aqui temos a presença da pretensiosa tentativa de reconstruções históricas a partir do texto do Apocalipse e mais um exemplo da maneira como o livro foi lido em terras latino-americanas. Como se 
percebe, a existência de sofrimento e perseguição serve como pano de fundo para a leitura do texto.

Mesmo que essas aproximações ao texto tenham contribuído com as pesquisas, as estratégias de leitura e perguntas ao Apocalipse de João estão mudando. Isso não desqualifica ou perde de vista a importância desses autores e obras. Não podemos deixar de admitir a gama de possibilidades de compreensão das imagens do Apocalipse acumulada por estes trabalhos e, também, o bom número de informações a respeito do contexto histórico e social do Mundo Antigo que essas pesquisas disponibilizaram.

\section{O Apocalipse como peça retórica para interpretação da natureza}

Desde o séc. XX, a pesquisa tem relativizado a imagem de um mundo cheio de violência e conflitos percebidos a partir da descrição do livro do Apocalipse, como se a obra equivalesse à situação concreta da vida das comunidades. Para importantes autores (alguns deles serão aqui apresentados) é mais frutífero olhar o livro do Apocalipse como estratégia narrativa, que acessa o discurso apocalíptico maior - que é uma constelação de tópicos (CAREY; BLOOMQUIST, 1999) — para persuasão retórica.

A superação da defesa da ideia de perseguição sistemática no Império Romano começa com uma percepção simples: não há muitas informações confiáveis (NOGUEIRA, 2011, p. 223). O primeiro indício claro de perseguição institucional por parte dos romanos está testemunhado na Carta de Plínio a Trajano (111-112 d. C.), um documento escrito pelo governador Plínio da Bitínia, no qual encontramos teor de inexperiência, como se antes não existisse esse tipo de relação com o Império:

Nunca presenciei nenhum julgamento de cristão. Por isso ignoro as penalidades e investigações costumeiras, como as pautas em uso. Tenho muita dúvida a respeito destas questões, tais como: estabelece-se diferença e distinções de acordo com a idade? Cabe o mesmo tratamento a enfermos e robustos? Aqueles que se retratarem devem ser perdoados? (Ep. X, ad Trajano, XCVI) (BETTENSON, 2001, p. 28-29). 
Leonard Thompson, depois de analisar as afirmações e argumentos de Eusébio à luz dos textos romanos e das tradições judaicas e cristãs, chega à seguinte conclusão:

Por razão em cada um dos pontos acima, a visão de Eusébio é insustentável. Domiciano não era um tirano. Há poucas evidências de que ele tenha perseguido cristãos. E a noção de que baniu João para a Ilha de Patmos não tem credibilidade (THOMPSON, 2003, p. 34).

Nos Oráculos Sibilinos (no livro 12), por exemplo, o reino de Domiciano é caracterizado como um "grande reino", de que "todos se agradarão" (THOMPSON, 2003, p. 30). Isso mostra que o tempo de Domiciano não era odiado, mesmo em um texto tão antirromano com os Oráculos Sibilinos (em especial o livro 5).

Mesmo as referências à morte de Antipas (Ap 2,13) e à multidão que vem da grande tribulação (Ap 6-7) não são provas de uma perseguição, pois além de estarem em linguagem escatológica, como uma expectativa, o que é próprio da linguagem apocalíptica, não revelam uma situação vivida em termos estruturais, sendo "meramente simbólicas", como é comum na linguagem religiosa (NOGUEIRA, 2003, p. 223). Caso houvesse uma perseguição generalizada, teríamos que explicar, tal qual indicou Nogueira, como temos na Ásia Menor uma postura favorável ao Estado e à sociedade.

Pelo que parece, antes do período da epístola de Plínio a Trajano não faria muito sentido pensar em perseguição. Isso é importante para pesquisa, pois se observa o Apocalipse dentro de circunstâncias narrativas e não histórico-sociais. Por isso a investigação sobre o livro seguiu outros caminhos, os quais pensam o contexto como semiosfera e o texto como realidade discursiva.

Outra obra que segue como uma renovação das pesquisas do Apocalipse é a de Adela Y. Collins (COLLINS, 1984). Essa autora descreve o ambiente do livro do profeta João como crise percebida. Ela defende que não há oficialmente tortura, morte ou prisão de cristãos pelo Império Romano, mas um conflito entre a fé em Jesus e o contexto social percebido pelo profeta João. Assim, o Apocalipse não é livro de consolação para os que sofrem perseguição por ordens imperiais ou por negarem obrigações religiosas (culto imperial), mas João provoca a crise a partir de um universo 
simbólico que somente ele poderia perceber (COLLINS, 1984, p. 77). Para ela, João cria a crise e diante da leitura do texto se geraria catarse.

A. Collins defende que a própria estrutura de recapitulação de imagens no Apocalipse serve para aguçar o ressentimento contra Roma, os judeus e os rivais dos grupos cristãos (COLLINS, 1984, passim). Criando ressentimento, o livro promove, também, a catarse na certeza do julgamento do glorioso futuro para os fiéis, a qual acalma a irrupção de inquietação criada pela própria narrativa. A sua hipótese abre possibilidades de se perceber o Apocalipse como estratégia narrativa e não reflexo que subjaz à realidade do Império Romano. Além disso, mostra-nos a importância da estrutura para a leitura do texto, que neste trabalho defenderá a criação de terror.

Com Elisabeth Schüssler Fiorenza se impõe a leitura dos símbolos e imagens do Apocalipse como estratégias retóricas (FIORENZA, 1998; FIORENZA, 1986). Em suas pesquisas, ela defende que há no Apocalipse a utilização retórica de imagens para a persuasão. Fiorenza argumenta que o poético e o retórico são diferentes. Obras poéticas se referem aos trabalhos que organizam ou criam experiências imaginárias, enquanto obras retóricas querem "persuadir" ou "movimentar" para certas ações (FIORENZA, 1986, p. 129). Não fazendo dualidades inocentes, Fiorenza afirma que existem textos que são retoricamente poéticos, ou seja, elementos poéticos e retóricos podem ser interlaçados em uma mesma obra. Nesse sentido, o Apocalipse é uma obra poético-retórica (FIORENZA, 1986, p. 130). A estratégia retórica como óculos para leitura das imagens do Apocalipse serve para responder à pergunta levantada por ela: se as perseguições são mesmo atuais ou são previstas, um perigo próximo. Ela questiona se o que realmente João quer é desestabilizar a complacência de alguns que prosperam durante o reinado de Domiciano (FIORENZA, 1998, p. 20). Sobre o caráter retórico do Apocalipse ela diz:

Ele procura persuadir e motivar através da construção de um "universo simbólico" que provoca participação imaginária. O poder de sua persuasão para a ação segue não na razão teológica ou argumento histórico, mas no poder "evocativo" de seus símbolos, assim como em sua exortação, imaginação, linguagem emocional, movimento dramático que se dedicam a provocar reações, emoções, convicções e identificação (FIORENZA, 1998, p. 187). 
Segundo a autora, o livro foi escrito como palavra profética para ser lido na assembleia. Um pouco diferente da leitura de A. Collins, Fiorenza diz que o Apocalipse serviu para criar uma nova estrutura de plausibilidade e "universo simbólico", como um mundo alternativo em face das perseguições ou possível execução. Nesse sentido, não há perseguição governamental, mas ostracismo social a que o universo simbólico do Apocalipse habilita os leitores a transcender.

O trabalho de Fiorenza permite ler o livro como instrumento de persuasão retórica, que lida com imagens para criar mundos e interpretar a realidade. No entanto, não é preciso seguir a hipótese de que há alguma perseguição ou até previsão. Assim, pode-se avançar para outro autor que leva isso mais adiante: Leonard Thompson (THOMPSON, 1986; THOMPSON, 1990).

Assim, a partir dos indícios narrativos de tribulação, Thompson mostra como estamos diante da construção retórica da realidade, a qual não reflete diretamente a realidade do mundo que cerca o visionário, mas é a "verdadeira" condição dos seus ouvintes à luz do mundo percebido pelo profeta. O conflito não está na perseguição ou qualquer privação, mas na divisão dos dois mundos criados discursivamente: o do profeta e o mundo romano (THOMPSON, 1986, p. 169).

O conflito sugerido por João não é entre elementos existentes no cristianismo, mas entre a sua compreensão de mundo e a do universo coerente encarnada no Império Romano. Roma oferece na esfera pública uma ordem coerente que une as realidades religiosa, social, econômica, política. [...] Roma oferece "conhecimento" por meio do qual os asiáticos urbanos poderiam "mover-se com certa confiança na vida cotidiana". O visionário julga que esse "conhecimento" público seja falso e oferece para os cristãos, por meio da verdade do Apocalipse, um conhecimento esotérico para integrar e ordenar suas vidas [...]. Ele procurou de várias maneiras possíveis afinar diferenças e distinções entre a sua visão de mundo e a romana, a fim de que seu conhecimento esotérico e verdadeiro não fosse confundido com ou diluído no falso conhecimento publicado pelo Império Romano. Tribulação como um tema hiperbólico no mundo literário de João funciona não como análise durante uma tensão entre fé e realidade sociopolítica, mas como uma expressão do conflito que ele percebeu entre os dois "mundos”. Sua oposição é expressa miticamente no simbolismo de João pela 
equivalência de Roma como o Mal, forças demoníacas opositoras à fé dos seguidores de Deus (THOMPSON, 1986, p. 166).

O Império Romano oferecia aos seus cidadãos a expressão retórica, materializada no Imperador e na Pax Romana, de ordem e coerência que unia os âmbitos sociais mais fundamentais da vida comum. Para o profeta João, essa ordem era falsa e deveria ser vista por outro ângulo, visionariamente, para se perceber o lado caótico que o sistema representava. Para dar autoridade ao seu discurso e leitura de mundo, ele começa seu texto demonstrando que tipo de força tem a sua narrativa: revelação de Jesus Cristo (1,1) (COLLINS, 1977).

O autor acredita que o problema esteja na retórica do Império e na interpretação do visionário. A paz e a prosperidade do discurso da sociedade romana, no seu ponto de vista, não podem ser celebradas pelos cristãos fiéis: as sete cabeças da besta são as sete colinas de Roma (Ap 17,9); elas também são sete imperadores romanos (Ap 17,10). Roma é Babilônia, a prostituta que cavalga a besta escarlate, que cai e que se tornou uma prisão (Ap 18,2; 20,7). No Apocalipse a ordem política de Roma é totalmente corrupta, pertencente ao reino satânico. Assim, Thompson defende que o conflito está na perspectiva de João, e não na sociedade. E ainda, a crise é uma orientação própria do gênero apocalíptico, e não necessariamente a realidade social. Como ele diz, a situação de crise é um topos no gênero apocalipse (THOMPSON, 1990, p. 175). Desse modo, Thompson mostra o Apocalipse de João como discurso que desqualifica retoricamente ao usar os topoi próprios do gênero para mostrar que o discurso de ordem e paz não era real, pois, por intermédio de meios autorizados, como a visão, interpreta-se o mundo romano de maneira completamente diferente. $\mathrm{O}$ que há são caos e perseguição prevista.

\section{Natural visto à luz do cósmico: caos e cosmos no Apocalipse de João}

Nas estratégias narrativas do Apocalipse se percebe, na sua forma, a relação de textos como fios unificadores internos do enredo que servem não somente a esse propósito, mas também como estruturadores do conteúdo de movimentação de caos e ordem - por exemplo, 17,1 e 21,9 mostram as relações de caos e cosmos (prostituta, esposa do cordeiro). 
Isso fica ainda mais claro com o surgimento do dragão, caído do céu com um terço das estrelas (12,3-4), e seu aprisionamento em 20,2-4.

Esse efeito de sentido é realizado, como está sendo dito, também pelo conteúdo. Os elementos semânticos desses quadros narrativos têm, como uma espécie de sintaxe para seus discursos, as memórias preservadas na semiosfera, estas em constantes explosões e encontros semióticos que alcançam suas potencialidades no Apocalipse de João.

Encontramos na obra diversos personagens no jogo dualista do caos e da ordem. Isso não é difícil de se perceber nos textos cosmogônicos que também faziam parte da memória cultural da tradição judaica e cristã e que foram traduzidos por diversas partes da semiosfera. Encontramos Pyton, Leto e Apolo; Sete, Isis, Horus; Tiamat, Marduc; Baal, Yam e outros. No livro do Apocalipse, nas seções das três séries de sete pragas, há a apresentação de personagens redondos tanto de um lado como do outro. Isso mostra, além da sua importância no desenvolvimento da narrativa, a saturação do ponto de vista narrativo do avaliador, que faz claramente o leitor dar as respostas satisfatórias de empatia, simpatia e antipatia. Por isso é possível convocar para sair daquele espaço que representa o lugar dos personagens de caráter antipático: "saí dela, ó meu povo" $(18,4 \mathrm{a})$.

Na linguagem das narrativas é perceptível a utilização do monstruoso e violento relacionada às expressões do caos. Essa linguagem está perpassada pelo grotesco. Segundo R. Graulund e D. Edward, o monstruoso é classificado como corpo grotesco por conta do seu caráter hibrido, composto por diferentes elementos. A figura física grotesca mistura o humano com o não humano, o que tem significado de corrupção (GRAULUND; EDWARD, 2013, p. 37): os atributos humanos das figuras grotescas são combinados com formas distorcidas e desproporcionais, as quais incorporam o animalesco ou, em alguns casos, formas vegetais de vida. Esses estudiosos continuam caracterizando o grotesco no monstruoso, revelando que tais seres costumam habitar em lugares distantes (GRAULUND; EDWARD, 2013, p. 41). A imagem do repulsivo, revelada pelas formas misturadas, reflete o interior da criatura, sua monstruosidade interna se mostra na violência e na brutalidade (GRAULUND; EDWARD, 2013, p. 39). Analisando as figuras homéricas, Graulund e Edward assinalam que a carnificina e o muito sangue são próprios do lugar do grotesco. Essas 
figuras, mesmo que mostrem os limites da corporeidade, têm a função do terror e do medo: "mas elas podem também gerar medo, ainda que para a estabilidade, por meio da descrição assustadora" (GRAULUND; EDWARD, 2013, p. 40).

O grotesco intenta demarcar identidade: o outro, o diferente. Verifica-se a demonização do outro, a desqualificação. O monstruoso, deformado, híbrido, misturado tem relação com o terror e o medo na definição cultural do outro, do corpo e da cultura na "grotescalização". Nesse sentido, o Apocalipse de João mostra a realidade de Roma a partir da realidade. O grotesco revela a interpretação que o visionário faz do sistema romano: monstro do caos, aterrorizante, híbrido e desestabilizador. Qualquer adequação seria um absurdo, porque tal relação não é aceitável — isso se os ouvintes previstos por João quiserem ser livres das pesadas e aterrorizantes mãos dos que não são do cordeiro $(9,4 ; 14,14$ et seq. etc.). O grotesco, também presente nos textos da cultua, mostra a identidade construída pelo visionário. Para que sua interpretação seja valiosa, ele precisa acessar uma sabedoria além-mundo, por intermédio da qual se pode ver o que não é visto, interpretar radicalmente a realidade, gerando peso à autoridade do narrador, aqui onisciente.

\section{0 caótico, o monstruoso e o mundo que virá: antítese do cosmos}

Depois da abertura epistolar (1,1-3), da visão gloriosa de João e do envio das cartas às igrejas $(1,4-3,22)$, começa o quadro de terror e punição por meio das pragas em série de sete. Como temos mostrado, elas estão interconectadas por indícios narrativos na estrutura maior de caos-ordem. Contudo, em termos de sincronia narrativa, 4,1-11 é um quadro de ordem em linguagem litúrgica: ser celestial sentado, organização de anciãos, os sete espíritos de Deus, os viventes, a kedushá, os seres viventes. No capítulo 5 começa o drama que tem início na apresentação do rolo com os sete selos (5,1). Após uma exposição densa de adoração (5,6-14), 6,1 volta à cena dramática do rolo e dos selos, o que desencadeia um conjunto de julgamentos com um misto de ação maligna, punição divina e salvação definitiva dos fiéis. Em 6,1-16,16, com uma conclusão da seção anterior e abertura para a posterior (16,17-21), há uma descrição da tensão entre o 
caos e a ordem, tendo o cap. 12 como ponto importante para esse quadro. Em 16,17-22,9 se verifica o início e o ápice da organização do mundo imaginado por João, que culmina na Nova Jerusalém (21-22,9).

As partes da seção com as pragas, as três séries, estão interconectadas por causa das estratégias de ricochetes e fio condutor. O sétimo selo

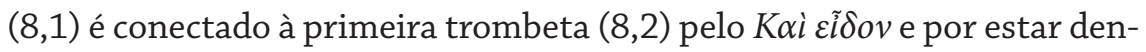
tro do sétimo selo. Dentro das trombetas estão 10-11,19 formando os dois primeiros "ais". As taças são introduzidas pelo bloco 12-14, que se liga por $\sigma \eta \mu \varepsilon \tilde{c} o v ~ \mu \varepsilon ́ \gamma \alpha(12,1 ; 15,1)$. 12,1 e 15-16 são vinculados narrativamente às primeiras duas pragas por 11,19 a com 15,5.

As séries das pragas no Apocalipse são aplicações escatológicas das pragas do Egito (Ex 7-12). Inclusive, se entre a sexta e sétima trombetas está 10-11,13, no livro do Êxodo, entre a nona e a décima pragas se encontra a instrução sobre a páscoa (Ex 12) (AUNE, 1998, p. 499). Essas imagens da Bíblia Hebraica servem como condutoras para a leitura do caos, com a linguagem de terror ao lado das tradições apocalípticas. As pragas atingem todo o cosmos, das relações sociais às estruturas naturais. Estas vivem as condições finais da existência, como estava previsto no Testamento de Dan 5,9, que antevê a punição por $\pi \dot{\alpha} \sigma \alpha \varsigma \tau \dot{\alpha} \varsigma \pi \lambda \eta \gamma \dot{\alpha} \varsigma$ Aijú $\tau \tau o v$ (todas as pragas do Egito). Em 3 Apocalipse de Baruc 16,3 se fala de gafanhotos, lagartas, ferrugens, granizo e relâmpagos como punição aos filhos com demônios (AUNE, 1998, p. 500). Essas imagens podem ser analisadas, bem como as ocorrências do discurso de construção do caos, com as imagens próprias da semiosfera judaico-cristã, tal como foi exposto no capítulo 2.

\section{0 caos instaurado!}

O Livro do Apocalipse interpreta narrativamente o mundo. Como bem percebeu José Adriano Filho, "o Apocalipse deve-se principalmente à linguagem mítica que o livro utiliza, principalmente a do conflito primordial, que indica a instalação das forças demoníacas na esfera política e humana, transformando-a num verdadeiro caos" (ADRIANO FILHO, 1999, p. 100). Se há um discurso de ordem, no qual Roma promove a sua estrutura imperial, João vai ao céu, como nos textos de viagem além- mundo 
(THOMPSON, 1990, p. 193), e acessa uma sabedoria maior para legitimar a sua contranarrativa. Thompson chama as narrativas maiores, as do sistema romano, de "conhecimento majoritário". O narrador faz a sua crítica pública da falsa ordem de mundo (DUFF, 2011, p. 9) a partir da semiosfera judaico-cristã, a qual preserva imagens e expressões de caos em estrutura topográfica dos textos canonizados na cultura, outras da literatura bíblica e os espetáculos romanos (FRILINGOS, 2004, p. 11).

Dessa forma, pode-se entrar nas visões e seus conteúdos para se perceber como o narrador, pelo menos enquanto autor implícito, pressupõe as memórias na cultura e como ele as articula para a construção do terror. Paul Duff, ao falar dos capítulos 6 e 9, acerta quando diz que João faz acusações ao seu rival por meio da retórica da insinuação ao utilizar homologia e ironia, as quais emprega em todo o Apocalipse para construir o seu mundo dualista narrativamente. No entanto, ele erra em achar que a questão seja uma querela interna. Fazendo uma leitura feminista, Duff acredita que seria uma linguagem injusta de violência contra a liderança de Jezabel e seus seguidores (DUFF, 2011, p. 16). Não há dúvidas de que as cartas estão em diálogo polêmico com alguns líderes nas comunidades, mas é a questão da aproximação com interesses do Império e a aceitação do discurso de ordem romana que constitui o seu grande problema. As pragas, além de revelarem o caos como verdadeira realidade, são também expressões das punições aos que não têm a marca $(9,4)$, aos que desejam o desestímulo à assimilação do discurso ou, como diria Thompson, o conhecimento público romano.

No capítulo 6,1-7 o livro é aberto. A liturgia de 9b-14 é um interlúdio dramático que cria o suspense necessário para a abertura dos selos. $\mathrm{O}$ mesmo cordeiro $(5,6)$, que é actante da ação transformadora, inicia abertura dos selos. A história será descortinada como um filme, com cenas ligadas umas às outras. Os quatro primeiros selos representam quatro cavalos. O primeiro, branco; o segundo, vermelho; o terceiro, negro; o quarto, verde. Esses cavalos trazem à memória Zc 1,7-11 (AUNE, 1998, p. 390). O primeiro selo traz um cavalo branco com força, com liderança e vitória. O cavalo vermelho tem em sua cavalgadura um montador com

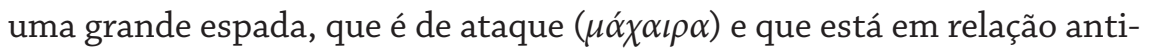

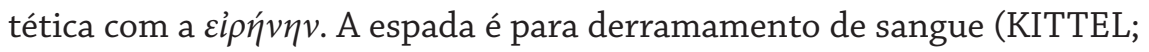


FRIEDRICH; BROMILEY, 1995, p. 525). Esse instrumento é somente um complemento da sua capacidade de criar as intrigas necessárias entre os homens, a fim de que se matem. Em 1En 10,12 os gigantes são colocados uns contra os outros para serem destruídos: "coloca-os uns contra os outros, para que se matem mutuamente". Se em 1 Enoque era uma ação de ataque aos causadores de caos, aqui a imagem serve para mostrar a instauração e revelar como o narrador lê as relações sociais. Sobre o cava-

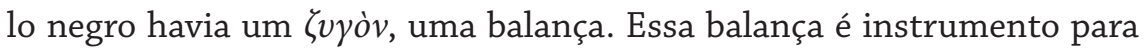
medir a inflação dos preços, numa imagem de caos nos valores dos bens básicos tanto para as pessoas (trigo) como para os seus animais (cevada). O valor de um salário do dia revela o descontrole de preços próprio dos momentos de fome ou de guerra (AUNE, 1998, p. 397). Usando a segunda pessoa do aoristo ( $\dot{\alpha} \delta \imath \kappa \eta ́ \sigma \eta ฺ)$ ), é dada a ordem para o cavaleiro não causar problemas inflacionários ao vinho e ao óleo $(6,6)$, que seriam os produtos de luxo, mostrando ainda mais a realidade de desigualdade de valores e a desordem econômica. O cavalo verde é montado pela morte $(6,7)$, uma personalização da realidade de destruição causada pelas espadas e balanças dos cavalos anteriores. O hades, lugar dos mortos na tradição grega, é personagem figurante na narrativa, enquanto a morte é protagonista causada por diversas forças: espada, fome, peste e feras.

O quinto selo abre uma nova cena na narrativa. Se até 6,8 o texto não dá detalhes do espaço dos verbos, aqui as personagens coletivas, "as almas imoladas”, estão no altar, lugar do sacrifício. O caos narrativo dos quatro primeiros selos não atinge somente os ímpios, os que não têm a marca de 9,4 , mas tem impacto até sobre os justos. Por causa da Palavra $(6,9)$, prevê-se que essa situação de paz anunciada não representa o que está prestes a acontecer. Mártires serão os que entendem a interpretação do visionário de se afastarem das relações com o Império e seus discursos. Eles são tratados de forma especial porque são personagens com os mesmos traços do cordeiro $(4,6)$ que abre os selos. Quem tem o poder de abrir os selos também beneficia seus pares. Narrativamente se cria um espaço de tempo entre o quarto e o quinto selos, bem como entre a quarta e a quinta trombetas, pois esse sexto selo será a intensificação da cena de terror e caos.

É nesse espaço-tempo da narrativa que se nota uma das imagens enoquitas de instauração de caos que se perenizou na semiosfera e que 
aparece na construção narrativa de João. Há um terremoto, o sol torna-se negro, a lua inteira se torna como sangue e as estrelas caem do céu, precipitando-se sobre a terra $(6,12)$. Como desdobramento, o céu é enrolado tal qual um pergaminho, montanhas e ilhas são removidas, todas as pessoas de diversas classes sociais são aterrorizadas e pedem a morte, porque melhor seria morrer do que enfrentar o dia da ira do cordeiro $(6,16)$.

A imagem das estrelas caindo joga com a ambiguidade presente no termo $\alpha \sigma \tau \eta \rho$ e com os textos da cultura judaica e cristã. Isaías 34,1-17, ao descrever o julgamento de Edom, fala sobre o exército do céu apodrecer usando o niphal (لِّرِ para mostrar que, tal como uma fruta apodrece, assim cairiam as estrelas do céu. O texto ainda esclarece isso no verso 4 usando um paralelismo sinonímico ao dizer que esse exército cairá

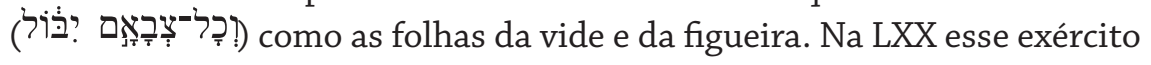
é traduzido como $\tau \dot{\alpha} \alpha \ddot{\alpha} \sigma \tau \rho \alpha$, "estrelas". No apocalipse de Marcos $(13,21)$, com seus paralelos em Mt 24,29 e Lc 21,26, as estrelas que caem são apresentadas em linguagem escatológica. Por isso essas estrelas, que poderiam ser simplesmente astros do céu, às vezes representando governos (Is 14; 34), ganham conotações escatológicas. Em 1En 86,1-2 a estrela que cai é um ser celestial precipitado do céu e que se transforma em um animal, bem como as demais estrelas do mesmo capítulo. No Livro Astronômico (1En 72-82) estrelas e anjos se confundem. Assim, falar em estrelas que caem do céu é, provavelmente, na semiosfera judaico-cristã, expressão de desordem cósmica localizada em temporalidade escatológica. No livro do Apocalipse $(8,10 ; 9,1 ; 12,4)$ estrelas que caem do céu são seres precipitados dos céus e que têm forças de desordem.

Assim sendo, o movimento de estrela em queda é vinculado e está em diálogo com textos da cultura, bem como ativa memórias em relação dialógica com o Apocalipse. Essa realidade do caos é percebida $(6,17)$ como o início do "grande dia da sua ira". O texto confirma a imagem do começo do bloco (4-5), que é o controle do cordeiro, pois esse momento de terror interpretado pelo visionário tem espaço para uma expectativa de fim, também interpreta a realidade, torna-se uma narrativa de instauração de caos. O mundo é, para João, estrelas que caem do céu — está em caos.

A narrativa, para gerar mais tensão e expectativa sobre o leitor implícito, cria a cena de 7,1-17, que pode ser lida como continuidade do sexto 
selo. No sétimo selo estão inseridas as sete trombetas. No céu o cordeiro abre o selo e ocorre um silêncio $(8,1)$. Esse tempo de espera, com o uso da conjunção grega de comparação ( $\dot{\omega}$ ) (ARNDT; DANKER; BAUER, 2000, p. 1104), é caracterizado como meia hora ( $\dot{\omega} \zeta \dot{\eta} \mu \iota \dot{\rho} \iota \mathrm{ov})$. Nesse ponto da narrativa temos uma elipse qualificada, mas que não determina, como acontece com tais estratégias narrativas, claramente esse período de tempo. $\mathrm{O}$ tempo de espera é comparado a meia hora da cronologia histórica, mas como a narrativa é construída no tempo mítico, ele não pode ser datado. É simplesmente uma indicação narrativa estratégica de tensão. Nos versos 2-5 há uma liturgia para o início das séries de trombetas: tem incensário e altar diante do trono, o que lembra 6,9-11. Essa é uma introdução para as cenas de terror que se seguirão, pois já são antecipadas pelo v. 5 .

A primeira trombeta é tocada e caem sobre a terra granizo e fogo $(8,6)$. Esses dois elementos, segundo as tradições de viagem além-mundo, estão no céu, no mesmo espaço do trono. Assim como no verso 5, os elementos do céu (fogo do altar) servem como munição para atacar a terra - eles estão misturados com sangue. Nessa trombeta, um terço da terra, das árvores e toda a vegetação se queimou. Na segunda trombeta uma montanha de fogo é lançada no mar e um terço dele se transforma em sangue: como consequência, um terço dos animais aquáticos são mortos e a mesma quantidade de embarcações. Vários aspectos do cosmos são destruídos (8,7.9-12; 9,15.18), gerando uma imagem de desordem que atinge pessoas, grupos, trabalhos e ecossistemas: a criação é abalada.

É nesse contexto narrativo que aparece o terceiro anjo e toca a trombeta. Nesse momento, diz o texto que uma grande estrela (como em 6,13), ardente como uma tocha ( $\alpha \sigma \tau \grave{\eta} \rho \mu \varepsilon \dot{\varepsilon} \alpha \varsigma \kappa \alpha \iota o ́ \mu \varepsilon v o \varsigma ~ \omega \varsigma ~ \lambda \alpha \mu \pi \dot{\alpha} \varsigma-8,10)$, cai sobre um terço dos rios e suas nascentes. Essa estrela é identificada com o nome 'A $\psi \iota v \theta 0 \varsigma$. Tal personagem é plana e caracterizada por um só traço - o seu próprio nome, o que é o bastante para descrever as suas consequências: a terça parte da água é convertida em absinto. Na Bíblia Hebraica (Dt 29,17; Lm 3,15; Jr 19,14; 23,15), ingerir essa substância extremamente forte e amarga seria um sinal de julgamento (ROLOFF, 1993, p. 111). O amargor das águas matou os homens. Nesse movimento de estrela, agora nomeada, seu nome é exatamente a sua consequência. À luz do que está dito acima, percebe-se que ideia de descer, cair em uma topografia inserida no tempo 
escatológico serve como conteúdo para mostrar a realidade prevista e já observada discursivamente na narrativa do visionário.

Na sétima trombeta, depois do segundo "ai" $(11,14)$, surge uma cena de batalha cósmica com clara linguagem do mito do combate do mundo antigo (COLLINS, 2001, p. 207-221). A narrativa, como tem feito até aqui, apresenta um narrador onisciente, que conhece as coisas que estão acontecendo nas esferas mais imperceptíveis. Ele narra que há um sinal no céu: uma mulher vestida com o sol, que tem a lua sob os pés, uma coroa de doze estrelas sobre a cabeça. Ela está grávida, com dores, aos gritos e em trabalho de parto (12,1-2). Essa mulher, como personagem redonda, fecha a descrição com detalhes sobre si. Surge outro sinal colocado ao lado do primeiro. É um ser também cósmico, um $\delta \rho \alpha ́ \kappa \omega \nu$ (dragão), cuja cor era de fogo, com sete cabeças, dez chifres e com dez coroas. Ele não está sozinho. Sua cauda derruba um terço das estrelas do céu, lembrando as pragas anteriores. Esse ser celeste é identificado no verso 9 como ó ö $\varphi \iota \varsigma$

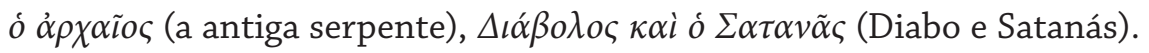
O ser grotesco ataca o filho daquela mulher (12,4-5). O menino, diz o texto, seria aquele que resgataria - ou governaria - as nações, o que será possível nos capítulos finais do Apocalipse. O menino é levado para o céu, junto ao trono divino, e a mulher foge para o deserto $(12,6)$. Depois disso, constrói-se uma imagem de batalha cósmica com duas forças opostas: de um lado o dragão e seus anjos (aquele um terço do céu - 12,4); do outro, Miguel e seus anjos. São duas forças: uma do caos e outra, da ordem.

Nas narrativas cosmogônicas da Mesopotâmia e nos mitos do combate no Mundo Antigo, o dragão representante do caos é destruído por sua contraparte e a ordem, que seria a criação, é instaurada. A ideia dos seres do caos contra Javé está em vários lugares da Bíblia Hebraica, que é uma imagem da criação. A mais conhecida é Gn 1,2, que fala do תִ: ת: (tehôm), o abismo primordial, e que tem ecos com a Tiamat da tradição cosmogônica mesopotâmica e outras do Mundo Antigo. Em Jó 26,12; Sl 74,12-13; Is 27,$1 ; 51,9-10$ e outros, Deus vence os seres ligados ao mar primordial, todos estes personagens do caos, o que possibilita a criação. A volta do cativeiro em Is 51,9-10 é interpretada cosmogonicamente: o caos é a experiência de exílio, que é resolvido com o retorno. Em Is 27,1 os seres vencidos por Javé são os seres do caos, o que a LXX traduz como dragão. 
Na LXX, Leviatã, serpente escorregadia, serpente torcida e Tannin são traduzidos pela expressão dragão; seres do caos que estão nas narrativas cosmogônicas e que aparecem na Bíblia Hebraica em alguns lugares em combate com Javé. Em Ap 12,7-12 se cria um dualismo rígido. De um lado as forças do caos: o dragão e um grupo de estrelas que ele arrastou. Do outro, Miguel e seus anjos. A batalha é vencida no céu e a ordem é restabelecida. Mas como o dragão cai na terra e continua a perseguição à mulher e seus filhos, ela ainda não chegou ao seu final primordial. Como nas narrativas preservadas na cultura, com seus temas de instauração de caos, especialmente na linguagem enoquita o ser ou seres que caem são forças que promovem o caos e desordem. As fronteiras são transgredidas e a realidade é descrita de maneira grotesca/monstruosa, como a imposição do dragão. Nos versos 13-17 a luta e a perseguição se estendem aos filhos da mulher porque o vômito de água não a destruiu. Roma é descrita como representante não da ordem, mas do caos. Há o contradiscurso no qual a linguagem mítica dá cores a uma realidade que existe no mundo da narrativa.

A batalha ainda não está no fim; ela agora se instaura na terra. Outro ser caótico surge no capítulo 13. Ele está associado ao dos caps. 12 e 17 por ter as suas características (12,2), receber o seu trono e sair do mar $(17,8)$. Essa besta que sai do mar lembra Dn 7 , que carrega a linguagem de seres caóticos vinculados ao espaço marítimo (Yam). Daniel, assim como João, caracteriza estratos governamentais como manifestações do caos. O dragão da linguagem mítica tem sua realização na terra; é a besta que sai do mar $(13,1)^{5}$. A ele também está vinculada a besta que sai da terra, que fala como o dragão $(13,11)$. A estas estão relacionadas outras duas: 11,7 e 17,9. Essas figuras são imagens ligadas com o sair das profundezas do abismo, que podem ser colocadas ao lado da expressão mar, de onde saem os seres caóticos.

Tais imagens impregnam a narrativa com o terror do caos. O visionário vê a presença na estrutura do sistema da própria realização das forças do dragão, que é o próprio Satanás das memórias apocalípticas. Para

5 Não é propósito deste trabalho entrar na discussão sobre o culto ao imperador e sua relação com o cap. 13. Contudo, para uma discussão a esse respeito, ver: STEVEN, 2003, p. 49-64. Quanto às relações das imagens com o tema do Nerus redivivus, ver: PEERBOLTE, 1996, p. 144-166. 
essa construção narrativa se emprega a ideia de seres que caem ou outros que sobrem do abismo. Eles não são vários, mas um que, narrativamente ligado por representações e repetições de imagens, interpreta a realidade miticamente: Roma é caos. Aqueles associados a ela e seus discursos seriam, também, fadados ao mesmo destino (17-19). O cântico de 14,6-8 é somente um presságio do que se concretizaria em 17-19: a queda da prostituta. Depois da última batalha $(19,11-21)$ acontece, então, a ordem do caos, o julgamento do ser caótico.

Para construir narrativamente a ordenação, em 20,1-4 o ser de caos é colocado no abismo. Essa topografia está na cultura como uma referência de ordenação e desordem. O caos se estabelece por conta da transgressão do que estava estabelecido e volta ao seu estado com o restabelecimento dos lugares cósmicos, como mostram as narrativas enoquitas. No entanto, essa ordenação de 20,1-3 é temporária, pois somente se estabelecerá de uma vez por todas, em linguagem escatológica, no julgamento de todas as coisas e das próprias formas da desordem que insistem na sua presença desastrosa (20,7-8). Os caps. 21-22 são a realização final da ordenação.

$\mathrm{Na}$ semiosfera judaica as narrativas da apocalíptica descreviam a instauração do caos com imagens de seres transgredindo suas fronteiras (1En 1-16 e sua recepção) e a sua neutralização com o aprisionamento no abismo. Na linguagem do livro do Apocalipse essa desordem é novamente pintada de forma narrativa. O mundo no qual o visionário está não vive uma perseguição estrutural. Prevendo e descortinando, ele percebe uma realidade mais oculta, que precisa de uma sabedoria mais celestial para ser acessada. O que parece ser uma ordem, para o visionário é caos. E isso vai se tornar ainda pior. Como diz Fiorenza, é uma interpretação "mitopoética" da realidade (FIORENZA, 1998, p. 22). Por isso os seus leitores implícitos são descritos como aptos a discernir e escolher entre aceitar a associação ou não com essas forças do caos. Em 18,1-3 estão os cúmplices, os beneficiados. Portanto os seus ouvintes são incitados a deixar, a não se associar $(18,4)$, pois a estes o que lhes resta é a punição com a Prostituta $(18,4 b-8)$. Desse modo, a narrativa cria dois grupos de personagens redondos: os que estão ao lado do discurso do narrador (a mulher, os santos, os 144.000) e os que aceitam o discurso do sistema vigente, que é caracterizado como dragão, serpente, bestas, ou seja, o próprio Satanás. 


\section{Considerações finais}

Como se percebeu, no livro do Apocalipse o narrador insere imagens de seres em movimentos espaço-temporais próprios da linguagem dos mitos do combate e da presença do caos. Observaram-se, então, as imagens de seres que caem, de outros que sobem das profundezas e os resultados de sua presença no mundo. O que ficou claro foi a formação de um quadro de instauração de caos, o qual é bastante perceptível em Ap 6-16. Em Ap 17-19 temos o início da diluição desse quadro e uma transformação final e ordenação completa em Ap 20-22. Esta é, na verdade, a destruição da Prostituta e o aprisionamento dos seres causadores da desordem cósmica. A visão apocalíptica era a negação e contradição da Roma eterna, a escatologia oficial do império (COLLINS, 2005, p. 18).

O Apocalipse privilegia a visão, sendo que ela está a serviço da relação performática entre narrativa e ouvintes: as imagens são agentes performáticos. Como intui Frilingos, quando Roma é descrita como besta e prostituta, sendo finalmente destruída (17-18), ao contemplarem essas imagens literárias, os espectadores narrativos participam no horrível quadro para desafiarem a audiência a dar performance na vida (FRILINGOS, 2004, p. 40-41).

Não há possibilidade de flexibilidade. A linguagem dualista não permite meio-termo. Guiado pelo narrador, o leitor deveria construir suas relações de empatia ou antipatia com os grupos de personagens. Isso determinaria a relação de simpatia, posição positiva com o dono do discurso representado por cada um dos grupos. Contudo, ele é muito contundente: "ou fuja do mundo construído pelo discurso do Império ou viva a possibilidade de sofrimento das punições no processo da nova criação", ou seja, "associe-se ao caos ou à ordem".

Neste sentido, o Apocalipse de João não observa a realidade como realização de funções naturais ou resultado de forças histórico-sociais. Pelo contrário, há um mundo paralelo que dá sentido e explica os

6 Para uma exposição desse dualismo como um uso retórico em uma perspectiva de gênero, cujo quadro, especialmente em 17-19, mostra a figura feminina associada às forças do caos, ver: FIORENZA, 2003, p. 243-269. 
movimentos mais comuns da vida, que para o visionário é acessado por meio da revelação.

Desta forma, a religião serve como um instrumento de perceber na articulação da história e movimentos da natureza a realização de expressões sobrenaturais, em um movimento contínuo de caos e ordem. No Apocalipse, em específico, Roma e seu funcionamento são resultados destas forças malignas e a elas representam. O caos está como ponto dado, uma realidade não visível, mas percebida apocalipticamente.

\section{Referências}

ADRIANO FILHO, J. Caos e recriação do cosmos: a percepção do Apocalipse de João. Ribla, n. 34, 1999.

ARNDT, W.; DANKER, F. W.; BAUER, W. A Greek-English Lexicon of the New Testament and Other Early Christian Literature. Based on Walter Bauer's Griechisch-deutsches Worterbuch zu den Schriften des Neuen Testaments und der frhchristlichen Literatur. Chicago: The University of Chicago Press, 2000.

AUNE, D. E. Revelation 6-16. Dallas: Thomas Nelson, 1998. (Word Biblical Commentary 52B).

CAREY, G.; BLOOMQUIST, G. L. (Ed.). Vision and Persuasion: Rhetorical Dimensions of Apocalyptic Discourse. St. Louis: Chalice, 1999.

COLLINS, A. The Combat Myth in the Book of Revelation. Eugene: Wipf and Stock Publishers, 2001.

COLLINS, J. Pseudonymity, Historical Reviews and the Genre of the Revelation of John. Catholic Biblical Quarterly, v. 39, n. 3, p. 329-343, Jul. 1977.

DUFF, P. Who Rides the Best? Oxford: Oxford University Press, 2011.

FIORENZA, E. S. The Book of Revelation: Justice and Judgment. 2. ed. Minneapolis: Fortress Press, 1998.

FIORENZA, E. S. Babylon the Great: A Rhetorical-Political Reading of Revelation 17-18. In: BARR, D. L. (Ed.). Reading the Book of Revelation. Atlanta: Society of Biblical Literature, 2003. p. 243-269. 
FRILINGOS, C. A. Spectacles of Empire: Monsters, Martyrs, and the Book of Revelation. Philadelphia: University of Pennsylvania Press, 2004.

GRAULUND, R.; EDWARD, D. J. The Grotesque. London; New York: Routledge, 2013. (The New Critical Idiom).

HANSON, P. The Dawn of Apocalyptic: The Historical and Sociological Roots of Jewish Apocalyptic Eschatology. Philadelphia: Fortress Press, 1983.

KITTEL, G.; FRIEDRICH, G.; BROMILEY, G. W. (Ed.). TDNT. Grand Rapids: W. B. Eerdmans, 1995. v. 4.

MESTERS, C.; OROFINO, F. O Apocalipse de São João: a teimosia da fé dos pequenos. Petrópolis: Vozes, 2002.

NEWSOM, C. A. The Development of 1 Enoch 6-19: Cosmology and Judgment. The Catholic Biblical Quarterly, n. 42, p. 310-329, 1980.

NOGUEIRA, P. A. de S. Imagens de violência no Apocalipse de João: os demônios-soldados de Apocalipse 9. In: NOGUEIRA, P. A. de S. Experiência religiosa e crítica social no cristianismo primitivo. São Paulo: Paulinas, 2003.

PEERBOLTE, L. J. L. The Antecedents of Antichrist: A Traditio-Historical Study of the Earliest Christian Views on Eschatological Opponents. Leiden; New York; Köln: E. J. Brill, 1996. p. 144-166.

RICHARD, P. Apocalipse: reconstrução da esperança. Petrópolis: Vozes, 1996.

ROLOFF, J. The Revelation of John: A Continental Commentary. Minneapolis: Fortress Press, 1993.

ROWLAND, C.; MORRAY-JONES, C. The mystery of God. Leiden/Boston: Brill, 2009.

ROWLAND, C. The open Heaven: A study of Apocalyptic in the Judaism and Early Christianism. London: SPCK, 1982.

STEVEN, J. F. The Beast from the Land: Revelation 13:11-18 and Social Setting. In: BARR, D. L. (Ed.). Reading the Book of Revelation. Atlanta: Society of Biblical Literature, 2003. p. 49-64. 
TERRA, K.

THOMPSON, L. L. A Sociological Analysis of Tribulation in the Apocalypse of John. Semeia, n. 36, p. 147-174, 1986.

THOMPSON, L. L. Ordinary Lives: John and his First Readers. In: BARR, D. L. (Ed.). Reading the Book of Revelation. Atlanta: Society of Biblical Literature, 2003.

THOMPSON, L. L. The Book of Revelation: Apocalypse and Empire. New York: Oxford University Press, 1990.

Recebido: 01/05/2017

Received: 05/01/2017

Aprovado: 28/09/2017

Approved: 09/28/2017 